\section{Pleasant memories: remembering immune protection while forgetting about graft-versus-host disease}

\author{
Paul M. Sondel, ${ }^{1,2,3,4}$ Ilia N. Buhtoiarov, ${ }^{2}$ and \\ Kenneth DeSantes ${ }^{1,4}$ \\ ${ }^{1}$ Department of Pediatrics, \\ ${ }^{2}$ Department of Human Oncology, \\ ${ }^{3}$ Department of Genetics, and \\ ${ }^{4}$ University of Wisconsin Comprehensive Cancer Center, University of Wisconsin, \\ Madison, Wisconsin, USA
}

\begin{abstract}
Graft-versus-host disease (GVHD) represents a major cause of morbidity and mortality following conventional allogeneic hematopoietic stem cell transplantation (HSCT). A study in mice (see related article on pages 101-108) demonstrates that the selective administration of donor memory $\mathrm{CD}^{+} \mathrm{T}$ cells results in immune reconstitution without GVHD, a result that, if translatable to humans, has important clinical implications for HSCT.
\end{abstract}

J. Clin. Invest. 112:25-27 (2003). doi:10.1172/JCI200319095.

Clinical transplantation of hematopoietic stem cells (HSCs) was first successful in $1968(1,2)$ and has provided life-saving therapy for potentially fatal diseases. These include acquired marrow aplasia, inherited dysfunction of hematopoietically-derived elements, and the iatrogenic marrow failure caused by supra-lethal chemo- or radiotherapy in the treatment of neoplasms. The goal of HSCT is stable engraftment of donorderived hematopoietic cells, allowing them to differentiate and function normally, while not causing destruction of host tissues by donor-derived immune cells, resulting in GVHD.

The presence of minor histocompatibility antigen (miHA) disparities between allogeneic individuals may induce GVHD, even when donor and recipient are matched at all MHC loci. Immunosuppressive drugs given after HSCT, or T cell depletion of the graft,

Address correspondence to: Paul M. Sondel, K4/448 University of Wisconsin

Comprehensive Cancer Center, 600 Highland

Avenue, Madison, Wisconsin 53792, USA.

Phone: (608) 263-9069; Fax: (608) 263-4226;

E-mail:pmsondel@wisc.edu.

Conflict of interest: The authors have

declared that no conflict of interest exists.

Nonstandard abbreviations used: graftversus-host disease (GVHD); hematopoietic stem cell (HSC); HSC transplantation (HSCT); minor histocompatibility antigen (miHA); chicken $\gamma$-globulin (CGG); T cell receptor (TCR); graft-versus-leukemia (GVL). GVHD (3). However,

Figure 1
GVHD), would have important clinical implications.

\section{Memory T cells do not cause GVHD in a miHA-disparate murine model} In this issue of the JCI, Anderson et al. (5) report on the coinfusion of purified $\mathrm{CD}^{+}$memory $\mathrm{T}$ cells in an MHCmatched, miHA-disparate, $\mathrm{T}$ celldepleted murine HSCT model. Their results conclusively show that unpurified $\mathrm{CD} 4^{+} \mathrm{T}$ cells cause GVHD, while the memory cells (defined here as CD44+ CD62 $\mathrm{L}^{-} \mathrm{CD}^{+}{ }^{+} \mathrm{T}$ cells) do not. Furthermore, memory $\mathrm{CD}^{+} \mathrm{T}$ cells taken from a donor immunized to chicken $\gamma$-globulin (CGG) retain their CGG-specific memory when the recipient of those memory $\mathrm{T}$ cells is immunized with CGG. In other words, these CD44+ CD62 $\mathrm{L}^{-} \mathrm{CD} 4^{+}$memory $\mathrm{T}$ cells remember how to respond to antigens to which they were primed but have "forgotten" how to react to allogeneic miHAs that are the targets of GVHD mediated by unfractionated or naive $\mathrm{CD} 4^{+} \mathrm{T}$ cells. absence of mature $\mathrm{T}$ cells, many months are required to re-create an intact $T$ cell immune system (4), leaving the recipient at great risk for opportunistic infection while a new $\mathrm{T}$ cell system arises from HSCs and undergoes thymic education (Figure 1). The ability to infuse donor $T$ cells that protect against infection and provide an antineoplastic effect, while excluding those $T$ cells responsible for damaging normal tissues (observed in

\section{Applicability to other strain combinations}

This finding provides some insight on the nature of alloreactivity. In this HSCT model, the $\mathrm{CD}^{+} \mathrm{T}$ cells responsible for GVHD are not in the CD44+CD62L$\mathrm{CD}^{+}$population (5). As such, the components of the $\mathrm{T}$ cell receptor (TCR) repertoire that recognize the miHAs may not be in the $\mathrm{CD} 44^{+} \mathrm{CD} 62 \mathrm{~L}^{-} \mathrm{CD} 4^{+}$mem-

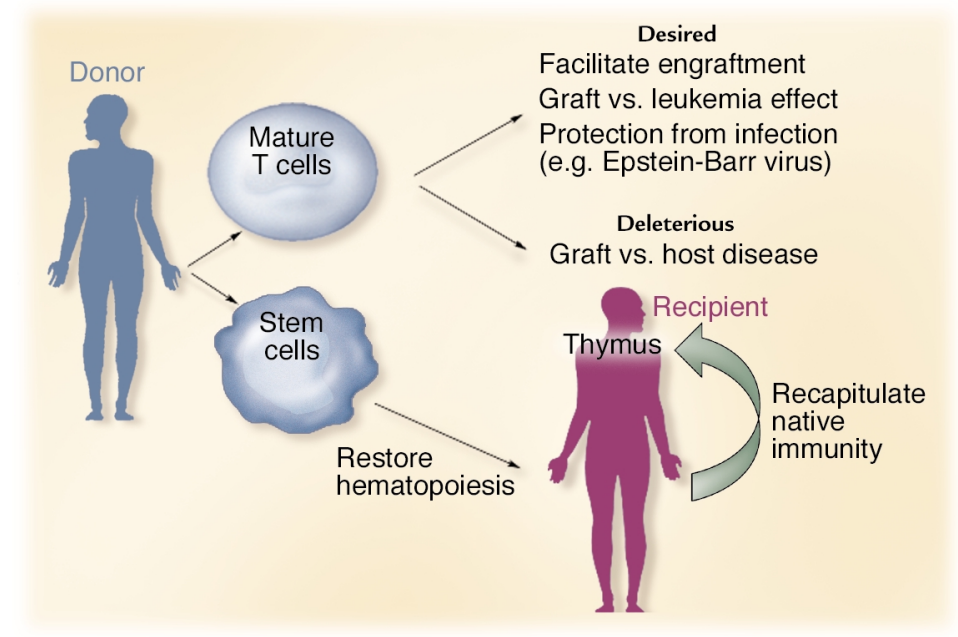

The donor graft contains both mature immune cells and primitive HSCs. T cells facilitate engraftment, protect against infection, and mediate an antileukemic effect. However, they may also initiate GVHD, a potentially fatal transplant complication. HSCs restore hematopoiesis and native immunity, the latter process requiring education of immune cells in the host thymus. 
ory $\mathrm{T}$ cell population. If so, the present study would suggest that the degeneracy of TCR recognition (6) does not extend to a cross-reactivity between the environmental antigens to which the donor's $T$ cells have been primed and the miHAs on allogeneic tissues of the host in this model system. It is essential that the GVHD-inducing potential of CD $44^{+} \mathrm{CD}_{62} \mathrm{~L}^{-} \mathrm{CD} 4^{+}$memory $\mathrm{T}$ cells be examined in a variety of other miHAand MHC-mismatched donor-host murine strain combinations. It seems likely that $\mathrm{CD}_{4} 4^{+} \mathrm{CD} 62 \mathrm{~L}^{-} \mathrm{CD} 4^{+}$memory $\mathrm{T}$ cells will still mediate GVHD in MHC-disparate hosts. This is because of the strength of the spontaneous $\mathrm{T}$ cell response to $\mathrm{MHC}$-incompatible tissue and the postulated immunologic cross-reactivity between allogeneic MHC molecules and environmental antigens being presented by autologous MHC molecules (7).

\section{Effector capabilities of CD44+CD62L-CD25-CD4+ memory $\mathrm{T}$ cells}

Alternatively, it remains possible that the $\mathrm{CD}_{4} 4^{+} \mathrm{CD} 62 \mathrm{~L}^{-} \mathrm{CD} 4{ }^{+}$memory T cells retain their ability to recognize miHAs but are missing the ability to mediate important effector functions involved in the initiation of GVHD. Using the landmark studies and memory cell differentiation pathways described by Lanzavecchia, Sallusto, and colleagues $(8,9)$, the population of $\mathrm{CD}_{4} 4^{+} \mathrm{CD} 62 \mathrm{~L}^{-}-$ $\mathrm{CD}^{2} 5^{-\mathrm{CD}} 4^{+}$memory $\mathrm{T}$ cells selectively infused by Anderson et al. (5) would be designated "effector memory cells" (Figure 2, lower left). These differ from the "activated effector cells" (Figure 2, upper right) by their less frequent expression of activation markers (i.e., CD25, CD49d, and CD69), and they differ from the central memory cells (Figure 2, upper left) by their loss of CD62L (L-selectin) and loss of CCR7, a chemokine receptor that facilitates homing to central lymphoid tissues. Thus the $\mathrm{CD}_{4} 4^{+} \mathrm{CD} 62 \mathrm{~L}^{-} \mathrm{CD} 4^{+}$effector memory $T$ cells are considered to be terminally differentiated cells that mediate some effector functions in the peripheral tissues but do not readily proliferate and do not induce central lymphoid activation $(8,10)$. In the absence of the other three $T$ cell populations shown in Figure 2, these cells might not be potent inducers of tissue destruction because of their in vivo pattern of distribution $(8-10)$, or the nature of the cytokines they release. These $\mathrm{CD} 44^{+} \mathrm{CD} 62 \mathrm{~L}^{-} \mathrm{CD} 4^{+}$ effector memory $\mathrm{T}$ cells appear to secrete more IFN- $\gamma$, IL-4, and IL-10 (inhibitory cytokines), and less IL-2 (an activating cytokine), than do central memory T cells (10).

Therefore the demonstration of retained CGG-induced proliferation by donor-derived reconstituted $\mathrm{CD}_{4}{ }^{+}-$ CD62L-CD4 ${ }^{+}$effector memory T cells in the host (5) does not necessarily translate to retention of protective immunity. It

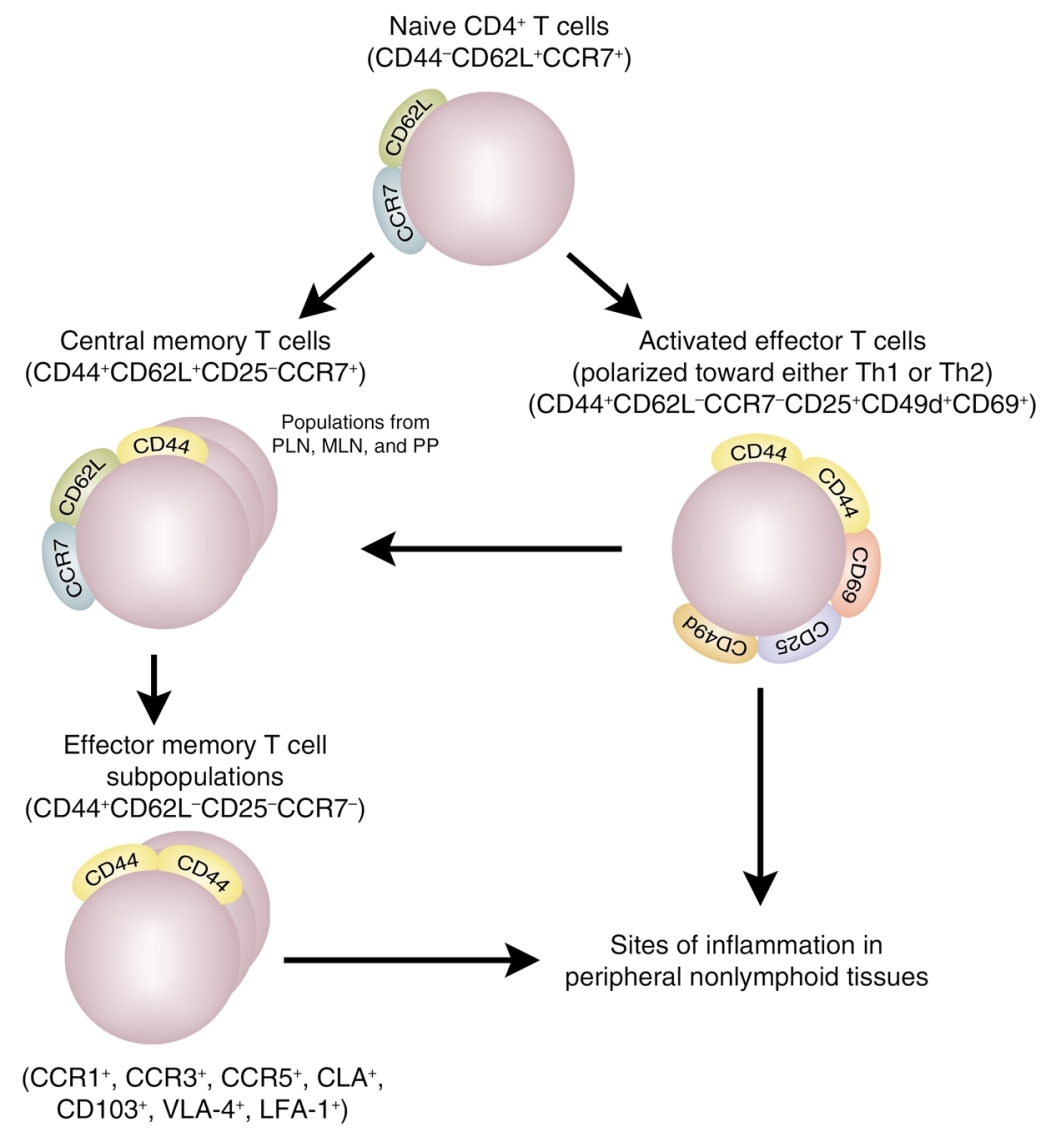

Figure 2

Stepwise differentiation of $\mathrm{CD} 4^{+} \mathrm{T}$ cells from naive $\mathrm{CD} 4^{+} \mathrm{T}$ cells to activated effector $\mathrm{CD} 4^{+} \mathrm{T}$ cells, and then to subsets of memory $C D 4^{+} T$ cells. These are divided into central memory $C D 4^{+} T$ cells $\left(\mathrm{CD} 44^{+} \mathrm{CD} 62 \mathrm{~L}^{+} \mathrm{CD} 25^{-} \mathrm{CCR} 7^{+}\right)$and effector memory CD4 ${ }^{+} \mathrm{T}$ cells $\left(\mathrm{CD} 44^{+} \mathrm{CD} 62 \mathrm{~L}^{-} \mathrm{CD} 25^{-} \mathrm{CCR} 7^{-}\right)$. $\mathrm{CD} 44^{+} \mathrm{CD} 62 \mathrm{~L}^{-} \mathrm{CD} 25^{-} \mathrm{CCR} 7^{-} \mathrm{CD} 4^{+}$effector memory $T$ cells represent a pool of terminally differentiated cells with heterogeneous immunophenotypes that express multiple patterns of chemokine receptors (i.e., CCR1, 3, or 5), tissue-specific homing receptors (i.e., CD103 and the cutaneous lymphocyte antigen [CLA]), and adhesion molecules (i.e., leukocyte function-associated antigen-1 [LFA-1] and very late antigen-4 integrin [VLA-4]), facilitating migration of these cells into different peripheral nonlymphoid tissues. The unique expression pattern and level of chemokine receptors, homing receptors, and adhesion molecules depend on the lymphoid origin (i.e., peripheral lymph nodes [PLNs], mesenteric lymph nodes [MLNs], or Peyer's patches [PPs]) of the effector memory T cells and the duration of TCR and cytokine stimulation. These features determine the migratory and homing preferences and functional capabilities of CD44 ${ }^{+}$CD62 $L^{-}$CD25-CCR7-CD4+ effector memory $T$ cells. 
phocyte infusions (15). Retaining the GVL effect while eliminating GVHD has been an elusive clinical goal. Additional testing is needed to determine whether CD $44^{+} \mathrm{CD} 62 \mathrm{~L}^{-} \mathrm{CD} 4^{+}$effector memory $\mathrm{T}$ cells might retain GVL activity, and whether specific immunization strategies of the donor might enhance transfer of protective immunity and GVL.

\section{Translation to clinical testing}

Finally, as pointed out by the authors (5), "if these murine results are applicable to human alloSCT, selective administration of memory $T$ cells could greatly improve post-transplant immune reconstitution." Before this is attempted clinically, murine $\mathrm{CD} 44^{+} \mathrm{CD} 62 \mathrm{~L}^{-}-$ $\mathrm{CD}^{+}$effector memory $\mathrm{T}$ cells still need to be tested in other strain combinations, evaluated for transfer of protective immunity, and tested for GVL potential. In addition, the immune capabilities of human $\mathrm{CD} 44^{+} \mathrm{CD} 62 \mathrm{~L}^{-}-$ $\mathrm{CD}^{+}$effector memory $\mathrm{T}$ cells must be studied in vitro and in adoptive transfer models (i.e., in immunodeficient or humanized mice) to determine whether their behavior parallels that of murine CD $44^{+} \mathrm{CD} 62 \mathrm{~L}^{-} \mathrm{CD} 4^{+} \mathrm{T}$ cells.

There is still much to do before we can forget about GVHD. The work of Anderson et al. (5) may be an important step toward that goal.

\section{Acknowledgments}

I.N. Buhtoiarov is supported by an International Union against Cancer-American Cancer Society international fellowship for beginning investigators.

1. Bach, F.H., Albertini, R.J., Joo, P., Anderson, J.L., and Bortin, M.M. 1968. Bone-marrow transplantation in a patient with the Wiskott-Aldrich syndrome. Lancet. 2:1364-1366.

2. Hong, R., et al. 1968. Immunological restitution in lymphopenic immunological deficiency syndrome. Lancet. 1:503-506.

3. Trigg, M.E., et al. 1985. Clinical trial depleting $T$ lymphocytes from donor marrow for matched and mismatched allogeneic bone marrow transplants. Cancer. Treat. Rep. 69:377-386.

4. Mackall, C., and Gress, R. 1997. Pathways of T-cell regeneration in mice and humans: implications for bone marrow transplantation and immunotherapy. Immunol. Rev. 157:61-72.

5. Anderson, B.E., et al. 2003. Memory CD4 ${ }^{+} \mathrm{T}$ cells do not induce graft-versus-host disease. J. Clin. Invest. 112:101-108. doi:10.1172/JCI200317601.
6. Leng, Q., and Bentwich, Z. 2002. Beyond self and nonself: fuzzy recognition of the immune system. Scand. J. Immunol. 56:224-232.

7. Mandell, R.B., and Sondel, P.M. 1985. Allele-specific alien-driven diversity, immune responsiveness and MHC-restriction. Immunol. Today. 6:321-323.

8. Lanzavecchia, A., and Sallusto, F. 2000. Dynamics of $\mathrm{T}$ cell lymphocyte responses: intermediates, effectors and memory cells. Science. 290:92-97.

9. Sallusto, F., Lenig, D., Reihold, F., Lipp, M., and Lanzavecchia, A. 1999. Two subsets of memory T cells with distinct homing potentials and effector functions. Nature. 401:708-712.

10. Hengel, R.L., et al. 2003. Cutting edge: L-selectine (CD62L) expression distinguishes small resting memory CD4+ T cells that preferentially respond to recall antigen. J. Immunol. 170:28-32.

11. Hogan, R.J., et al. 2001. Protection from respiratory virus infections can be mediated by antigen-specific CD4(+) $\mathrm{T}$ cells that persist in the lung. J. Immunol. 193:981-986.

12. Andersen, P., and Smedegaard, B. 2000. CD4+ T-cell subsets that mediate immunological memory to Mycobacterium tuberculosis infection in mice. Infect. Immun. 68:621-629.

13. Horowitz, M.M., et al. 1990. Graft-versus-leukemia reactions after bone marrow transplantation. Blood. 75:555-562.

14. Sondel, P.M. 2000. The graft vs. leukemia effect. In Allogeneic immunotherapy for malignant diseases. J. Barrett and Y.Z. Jiang, editors. Marcel Dekker Inc. New York, New York, USA. 1-12.

15. Slavin, S., et al. 1996. Allogeneic cell therapy with donor peripheral blood cells and recombinant human interleukin-2 to treat leukemia relapse after allogeneic bone marrow transplantation. Blood. 87:2195-2204.

\section{Preventing pathological regression of blood vessels}

\section{Eli Keshet}

Department of Molecular Biology, The Hebrew University-Hadassah Medical School, Jerusalem, Israel

\begin{abstract}
Oxygen administration to premature infants suppresses retinal VEGF expression and results in the catastrophic vessel loss associated with retinopathy of prematurity. A study investigating the development of the retinal vasculature in mice (see related article on pages 50-57) demonstrates that specific activation of VEGF receptor-1 by placental growth factor-1 protects against oxygen-induced vessel loss without stimulating vascular proliferation and neovascularization.
\end{abstract}

J. Clin. Invest. 112:27-29 (2003). doi:10.1172/JCI200319093.

\footnotetext{
Address correspondence to: Eli Keshet, Department of Molecular Biology,

The Hebrew University-Hadassah Medical School, Jerusalem 91120, Israel.

Phone: 972-2-6758496; Fax: 972-2-6757195; E-mail: keshet@cc.huji.ac.il.

Conflict of interest: The author has declared that no conflict of interest exists.

Nonstandard abbreviations used: retinopathy of prematurity (ROP); VEGF receptor-1 (VEGFR-1, also known as Flt-1); VEGF receptor-2 (VEGFR-2, also known as Flk-1); placental growth factor (PlGF); extracellular signal-regulated kinase (ERK).
}

A number of human disorders are associated with obliteration of preexisting blood vessels. Microvessel rarefaction often takes place in the hypertensive lung, in the myocardium of patients with chronic renal failure, and in the elderly. Conversely, a failure to eliminate transient embryonic vasculature destined for regression may lead to a disease, as exemplified by the common congenital developmental anom- aly of the eye, persistent hyperplastic primary vitreous, in which hyaloid vessels fail to regress. A striking example of a disease caused by vessel regression is retinopathy of prematurity (ROP). ROP is a blindness-causing neovascularizing disease that affects premature infants treated with high concentrations of oxygen. ROP develops in two distinct stages. First, the hyperoxic insult leads to obliteration of immature retinal vessels, thereby compromising retina perfusion. The second phase, initiated upon resumption of the breathing of normal air, is an adverse compensatory neovascularization response, mediated by ischemiainduced VEGF, in which formation of new vessels is excessive, neovessels are leaky, and the inner limiting membrane of the retina is breached, allowing vessel growth into the vitreous. The later event may ultimately lead to retinal detachment and vision loss.

\section{Protecting retinal vessels from oxygen-induced obliteration}

Why are newly formed blood vessels of the retina so vulnerable to excess oxygen? Vessel regression in ROP repre- 